\title{
Medical end-of-life decision-making in a small resource-poor Caribbean country: a mortality follow-back study of home deaths
}

\author{
Nicholas P. Jennings ${ }^{1,2}{ }^{*}$, Kenneth Chambaere ${ }^{1}$, Cheryl C. Macpherson ${ }^{3} \wedge$, Karen L. Cox ${ }^{4}{ }^{*}$, \\ Luc Deliens ${ }^{1,5}$, Joachim Cohen ${ }^{1 \wedge}$
}

${ }^{1}$ End-of-life Care Research Group, Vrije Universiteit Brussel (VUB) \& Ghent University, Brussels, Belgium; ${ }^{2}$ Bioethics Department, St. Geroge's University, St. George's, Grenada; ${ }^{3}$ Bioethics Division, St. George's University School of Medicine and Windward Islands Research and Education Foundation, St. George's, Grenada; ${ }^{4}$ Palliative Care Unit, Caura Hospital, North Central Regional Health Authority, Trinidad \& Tobago; ${ }^{5}$ Department of Medical Oncology, Ghent University Hospital, Ghent, Belgium

Contributions: (I) Conception and design: NP Jennings, K Chambaere, L Deliens, J Cohen; (II) Administrative support: Trinidad and Tobago Medical Association; (III) Provision of study materials or patients: None; (IV) Collection and assembly of data: NP Jennings; (V) Data analysis and interpretation: NP Jennings, K Chambaere, J Cohen; (VI) Manuscript writing: All authors; (VII) Final approval of manuscript: All authors.

* Nicholas P. Jennings and Karen L. Cox are nationals and residents of Trinidad and Tobago.

Correspondence to: Nicholas P. Jennings, MPH. Vrije Universiteit Brussel (VUB) \& Ghent University, End-of-life Care Research Group, Laarbeeklaan 103, 1090 Brussels, Belgium. Email: nicholas.jennings@vub.be.

\begin{abstract}
Background: In resource-poor countries, including in Latin American and the Caribbean, empirical information about the characteristics and incidence of medical end-of-life decisions (MELDs)—withholding or withdrawing potentially life-prolonging medical treatments-is largely absent.

Methods: The aim was to describe the incidence and decision-making characteristics of MELDs taken prior to the death of people who died at home in Trinidad and Tobago (T\&T). A mortality follow-back study was used where a representative sample of deaths occurring at home in 2018 was drawn from death certificates at the national death registry. The general practitioners who certified the deaths were sent a questionnaire.

Results: The sample consisted of 309 adult deaths and the response rate was $31 \%$ (N=96). Physicians were: mostly male (79.2\%), practiced medicine for more than twenty-years $(63.5 \%)$, had no formal palliative care training (69.8\%). Non-sudden deaths represented $76 \%(\mathrm{~N}=73)$, of these, medications to alleviate pain and symptoms in the last 7 days of life were administered in $65.8 \%$, including opioids $21 \%$. Potentially lifeprolonging treatments were withheld in $9.6 \%$ but none withdrawn. No physician/patient discussions about various end-of-life treatment options occurred in $61.6 \%$. Compared to physicians with no formal training in palliative care, those with training more often: prescribed or administered opioids in the last 7 days of life $(35.7 \%$ vs. $11.1 \%, \mathrm{P}=0.01)$, had discussions with patients about end-of-life treatment options $(60.7 \%$ vs. $24.4 \%, \mathrm{P}=0.002)$, and discussed medication use to alleviate pain and other symptoms with patients $(50 \% \mathrm{vs}$. $17.8 \%, \mathrm{P}=0.004)$.
\end{abstract}

Conclusions: Differences in the care and treatment general practitioners provided to their patients could be associated with them having been formally trained in palliative care. The necessary support to further develop palliative care in T\&T is needed.

Keywords: Shared decision-making; relatives; end-of-life care; ethics; general practitioner; Caribbean

\footnotetext{
$\wedge$ ORCID: Nicholas P. Jennings, 0000-0003-0045-5243; Kenneth Chambaere, 0000-0001-6277-072X; Cheryl C. Macpherson, 0000-0002-2368-
} 2089; Karen L. Cox, 0000-0001-5656-7354; Luc Deliens, 0000-0002-8158-2422; Joachim Cohen, 0000-0002-7224-9476. 
Submitted Jul 03, 2021. Accepted for publication Nov 03, 2021.

doi: 10.21037/apm-21-1793

View this article at: https://dx.doi.org/10.21037/apm-21-1793

\section{Introduction}

Advances in modern medicine can prolong life including the life of persons with degenerative or incurable illnesses. Medical end-of-life decisions (MELDs) are a hotly debated topic because prolonging life of terminally ill patients may not be the most appropriate or desired goal, but rather the quality of their life in the final days or weeks (1-4). MELDs can include: non-treatment decisions such as withholding or withdrawing potentially life-prolonging treatments no longer considered beneficial, intensification of medications administered to alleviate pain or other symptoms that may have unintended side-effect (rendering a patient unconscious or influence the timing of death), and physician-assisted suicide or euthanasia in countries or territories where this is legal (3-5).

Several factors are identified with influencing MELDs including attitudes and preferences of patients, their families and health care providers towards death and dying, and patient characteristics like age, gender, level of education and socio-economic status (6). Communication about endof-life care and MELDs can be difficult for physicians, patients, and their families as decisions are often perceived as 'life or death' (7). Increasing evidence suggests that appropriate care with low medical intensity near death is associated with more discussions between patients and their physicians about goals and expectations for medical end-oflife care $(8,9)$. In fact, communication and shared decisionmaking involving patients' input in planning their treatment promotes their satisfaction and compliance with care, improves relationships between health care providers and patients and is increasingly recognised as a quality indicator for care (10).

The need for good end-of-life care may be greatest in resource-poor countries, including Latin American and the Caribbean $(11,12)$, yet many who need it do not benefit because services are either limited or non-existent $(11,13)$. Resource-poor relates to the limited capability to provide appropriate care for life-threatening illness due to a lack of necessary human and material resources, inadequate education and training for health care providers, and a lack of governmental policies supporting the provision of palliative care $(12,14)$, including access to opioids for medical use (11). A good example is Trinidad and Tobago (T\&T), a small Caribbean nation where the provision of palliative care is considered "Isolated", that is, lacking a national commitment to palliative care and practice (12), absence of palliative medicine curricular at local universities, and data and infrastructure to generate reliable empirical information about the circumstances of dying from terminal illness is lacking $(14,15)$.

In countries with developed palliative care services general practitioners manage out-of-hospital care, they are instrumental in providing and coordinating palliative and end-of-life care for their patients preferring to stay at home (16-18), and can be supported by specialised palliative care providers (16). The use of specialist palliative care in home settings may be beneficial to patients and caregivers (19), but in resource-poor countries specialist services and support is lacking and people rely mostly on their general practitioners to provide home-based (generalist) care, supported by informal carers including family members. Research showed that general practitioners were the predominant provider of formal palliative care to persons dying at private homes from terminal illnesses in $T \& T$ (20).

In this study, we focus on MELDs taken prior to death in $\mathrm{T} \& \mathrm{~T}$, and will address the following research questions: (I) what is the incidence of different types of MELDs made for persons dying at home? (II) What are the characteristics of the decision-making process at the end of life? (III) Does end-of-life decision-making differ depending on the physicians' formal palliative care training? We present the following article in accordance with the STROBE reporting checklist (available at https://apm.amegroups. com/article/view/10.21037/apm-21-1793/rc).

\section{Methods}

\section{Design}

A population-based mortality follow-back study based on death certificates was done, where general practitioners had certified a sample of deaths occurring at home. In the last days or months of life, a retrospective design is an unobtrusive method to collect robust population-based information (21). A modified design of a European study protocol (22) was 
used. The study was conducted in accordance with the Declaration of Helsinki (as revised in 2013).

\section{Setting and participants}

A systematic random sample of $\mathrm{T} \& \mathrm{~T}$ residents aged 18 years or older, who died between March 1 and August 31,2018 at a private home was drawn from death certificates at the Central Statistical Office (CSO), the national death registry. In $T \& T$ physicians are obliged to certify a death and complete a death certificate, which is sent to the CSO for mortality statistics purposes. The sampling fraction, or the ratio of the sample to the population from which the sample will be drawn was 1 in 2, where every other case was selected from eligible death certificates. The general practitioner who certified a death in the sample was sent a questionnaire by postal mail about the care and decisionmaking in the specific case and invited to complete and return it. Multiple deaths could have been certified by the same general practitioner in our survey.

Our intended study included sampling home and hospital deaths. To test the feasibility of doing such a study at a hospital, a pilot study of deaths at a main governmenthospital was attempted. However, data collection was impeded by many structural barriers at the hospital including: time physicians had allotted to complete the questionnaire were delayed or interrupted because patient files were unavailable upon their request, and physicians either transferred between departments or from the hospital, which complicated the process of their receiving and completing a questionnaire. Consequently, this arm of the study became impractical to continue and was abandoned, we therefore focused only on home deaths.

\section{Survey instrument}

A questionnaire was developed building on a study in the Netherlands (4). By cognitive testing and validation, it was modified to ascertain it was suitable and relevant to the T\&T context, a previous study (23) explained and described the process in detail (including a version of the final questionnaire). Two filtering questions were asked at the beginning of the questionnaire, "was the patient death sudden", that is, totally unexpected due to natural causes and end-of-life care could not be ascertained (answer options: yes; no), and "when was the first contact the physician had with the patient" (answer options: at the time of or after death; before death). If answers were, respectively no and before death, general practitioners were asked to complete a three-page questionnaire on the care and treatment that preceded the death involved. Otherwise, they were asked to only provide sociodemographic information about themselves. Some key MELD questions considered in the questionnaire are shown in (Figure 1).

\section{Data collection procedures}

The sociodemographic information contained in death certificates includes the: sex, age, usual place of residence, date and cause of death of a decedent; the certifying physician completing a death certificate (which is paperbased) is also obliged to include their name and professional address. A maximum lag of three months between death of a patient and the general practitioner being asked to complete the questionnaire was allowed to minimise recall bias. The Trinidad and Tobago Medical Association (T\&TMA), an independent third-party, was involved in the mailing procedure. Their intermediary role between responding general practitioners, researchers and the CSO was to maintain physician anonymity and guarantee that completed questionnaires could never be linked to a particular patient or general practitioner. Moreover, patient sociodemographic information was anonymised and linked to the corresponding completed questionnaires (Figure S1). A maximum of three sampled cases with the same certifying physician was allowed, if a fourth case was sampled it was rejected but another case was resampled from deaths that occurred in the same month of the excluded case. Therefore, at most three questionnaires followed by two reminders (per questionnaire) were mailed to any one general practitioner. Additionally, resampled cases were excluded when the number of substituted cases were exhausted within the same month or the cut-off three-month time elapsed between a death and a questionnaire mailed to a physician. Also excluded from the sample were death certificates completed by community based primary care physicians who did not have access to the medical records of a decedent, such as county or district medical health officers. Death cases certified by; a post-mortem examiner, physicians who could not be contacted at their professional address or had retired during the data collection period, or who turned down voluntary participation in the study were also excluded. A delay of death certificates received by CSO from various district offices impeded our ability to sample cases, and data collection (sampling deaths and mailing questionnaires occurred between May 8 and December 27, 2018) was 


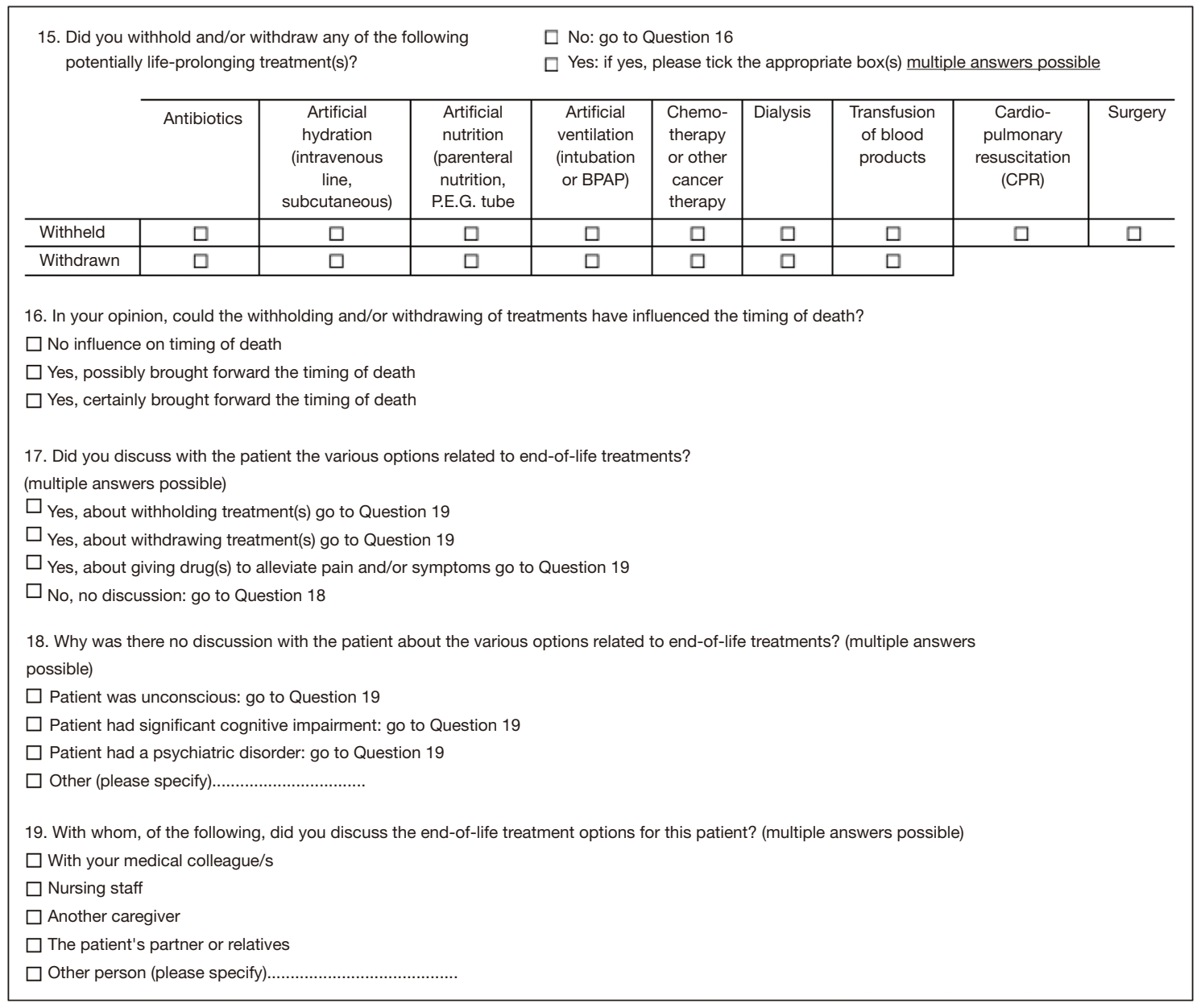

Figure 1 Key medical end of life decision-making questions. Questionnaire for mortality follow-back studies on end-of-life care and decision-making in a resource-poor Caribbean country, by Jennings et al., 2020, BMC Palliative Care. Copyright 2020. Reprinted with permission by the author(s) (23).

delayed due to a two-month lag in the CSO processing death records. Disruptions in the mail service also necessitated a one-month extension of the survey period. Microsoft Excel spreadsheets were used to record and collate questionnaire data that was sent and received by postal mail, which was later linked to the death certificate information by the T\&TMA. Ethics approval for the study was granted by the Ministry of Health of T\&T in January 2018.

\section{Statistical analysis}

Both SPSS and Excel were used for data cleaning and analysis. Sociodemographic information of attending general practitioners responding to the survey were grouped into the following categories: sex (female, male) and years of practice (less than $5,5-10,11-15,16-20$ years, more than 20 years). Their formal palliative care training was dichotomised; "no" and "other" were condensed into (no) and "yes, as part of my medical degree" and "yes, postgraduate training" into (yes). Frequency and cross tabulation analysis was used to describe associations. Chisquare tests were used to assess bivariate differences between end-of-life decision-making by general practitioners in relation to their formal training in palliative care, $\mathrm{P}$ values $<0.05$ were considered significant. SPSS 25 was used to compute these analyses.

\section{Results}

The sample drawn from available death certificates consisted 
Table 1 Characteristics of all general practitioners who responded to a questionnaire

\begin{tabular}{|c|c|c|}
\hline \multirow{2}{*}{ Variables } & \multicolumn{2}{|c|}{ Total $(\mathrm{N}=96)$} \\
\hline & $\mathrm{N}^{\dagger}$ & $\%$ \\
\hline \multicolumn{3}{|l|}{ Sex } \\
\hline Female & 20 & 20.8 \\
\hline Male & 76 & 79.2 \\
\hline \multicolumn{3}{|l|}{ Years of practice } \\
\hline Less than 5 years & 1 & 1.0 \\
\hline $5-10$ years & 10 & 10.4 \\
\hline $11-15$ years & 8 & 8.3 \\
\hline 16-20 years & 16 & 16.7 \\
\hline More than 20 years & 61 & 63.5 \\
\hline \multicolumn{3}{|l|}{ Formal training in palliative care ${ }^{\ddagger}$} \\
\hline $\mathrm{No}^{\S}$ & 67 & 69.8 \\
\hline Yes & 44 & 45.8 \\
\hline As part of my medical degree & 22 & 22.9 \\
\hline Post graduate degree & 22 & 22.9 \\
\hline
\end{tabular}

Expertise in communicating with patients at the end of life ${ }^{\ddagger}$

$\begin{array}{lll}\text { No } & 15 & 15.6 \\ \text { Yes } & 86 & 89.6 \\ \text { Through experience/informal training } & 75 & 78.1 \\ \text { Through formal training } & 11 & 11.5\end{array}$

Expertise in communicating with family of patients at the end of life ${ }^{\ddagger}$

$\begin{array}{lcc}\text { No } & 10 & 10.4 \\ \text { Yes } & 90 & 93.8 \\ \text { Through experience/informal training } & 81 & 84.4 \\ \text { Through formal training } & 9 & 9.4\end{array}$

Physician feeling of support by current protocols of care in Trinidad and Tobago preferred management and decision-making"

$\begin{array}{lll}\text { No } & 71 & 75.5 \\ \text { Yes } & 23 & 24.5\end{array}$

${ }^{\dagger}$, total numbers represent death cases, hence, the same general practitioner might have reported on multiple cases (maximum of three cases per general practitioner); ${ }^{\ddagger}$, multiple answers possible, hence percentages do not add up to $100 \%$; , an "other" category was included as an answer option, however, responses (continuous medical education, conferences and workshops and seminars) suggested no formal palliative care training; " , 2 missing. of 309 deaths, which represents $21 \%$ of all recorded adult deaths that occurred at a private home during the study period. 96 questionnaires (31\%) were returned completed (Figure S2). There was no significant difference in cause of death and sociodemographic characteristics between the obtained sample and all home deaths in the corresponding period (Table S1). The attending general practitioners of the included cases were mostly male $(79.2 \%)$, practiced medicine for more than 20 years $(63.5 \%)$, and had not received any formal palliative care training (69.8\%). Most considered that their communication expertise with patients $78.1 \%$ and patients' family members $84.4 \%$ was gained through experience and informal training (Table 1). Additionally, $75.5 \%$ of physicians feel unsupported by current national protocols concerning the preferred medical management of their terminally ill patients.

Seventy-three $(76 \%)$ deaths were reported as nonsudden, hence, a MELD by the general practitioner was theoretically possible in these cases. In $34.2 \%$ of these no medications were used to alleviate patient symptoms in the last 7 days of life (Table 2). But when given, the most common were Morphine or other opioids 20.5\% and Diazepam or other benzodiazepines $17.8 \%$. In over $82 \%$ of the cases when medications were administrated in the last 7 days of life, they had no influence on the timing of death, or possibly delayed the timing of death. Of the nontreatment decisions, no treatments were withdrawn but lifeprolonging treatments were withheld in 7 (9.6\%) deaths. The most common withheld treatments were artificial hydration and artificial nutrition $6.8 \%$ followed by artificial ventilation and cardio-pulmonary resuscitation $4.1 \%$.

There were no discussions between general practitioners and patients about decision-making on various end-oflife treatment options in $45(61.6 \%)$ deaths, but when discussions occurred, the most common were about giving medications to alleviate pain and/symptoms 22 (30.1\%), withholding treatments $10(13.7 \%)$ or withdrawing treatments 3 (4.1\%) (Table 3). Apart from the general practitioner, other caregivers involved in discussions were, the partner or relatives of the patient $55(75.3 \%)$ or medical colleagues $8(11 \%)$. Some patients $8.2 \%$ did express a wish for the end of life to be hastened, but only $2.7 \%$ did so explicitly to their general practitioner.

General practitioners who had formal training in palliative care, either as part of their medical degree or through a postgraduate programme, were more likely to prescribe or administer opioids in the last 7 days of life $35.7 \%$ than 
Table 2 Types and frequency of end-of-life decisions made by general practitioners for non-sudden deaths

\begin{tabular}{|c|c|c|}
\hline \multirow{2}{*}{ End-of-life decisions } & \multicolumn{2}{|c|}{ Total $(\mathrm{N}=73)$} \\
\hline & $\mathrm{N}$ & $\%$ \\
\hline \multicolumn{3}{|l|}{ Medications administered in the last 7 days of life } \\
\hline No & 25 & 34.2 \\
\hline Yes $^{\dagger}$ & 48 & 65.8 \\
\hline Morphine or other opioid & 15 & 20.5 \\
\hline Diazepam or other benzodiazepine & 13 & 17.8 \\
\hline Antiemetic & 10 & 13.7 \\
\hline Laxative & 9 & 12.3 \\
\hline Dopamine or other vasopressors & 1 & 1.4 \\
\hline Other $^{\ddagger}$ & 20 & 27.4 \\
\hline \multicolumn{3}{|l|}{ Influence on timing of death in the last 7 days of life ${ }^{\S}$} \\
\hline No influence on timing of death & 48 & 65.8 \\
\hline Possibly delayed timing of death & 12 & 16.4 \\
\hline Possibly brought forward timing of death & 0 & 0 \\
\hline Certainly brought forward timing of death & 0 & 0 \\
\hline Treatments withdrawn & 0 & 0 \\
\hline \multicolumn{3}{|l|}{ Treatments withheld } \\
\hline No & 66 & 90.4 \\
\hline Yes $^{\dagger}$ & 7 & 9.6 \\
\hline Artificial hydration (intravenous line, subcutaneous) & 5 & 6.8 \\
\hline Artificial nutrition (parenteral nutrition, P.E.G. tube) & 5 & 6.8 \\
\hline Artificial ventilation (intubation or BPAP) & 3 & 4.1 \\
\hline Cardio-pulmonary resuscitation & 3 & 4.1 \\
\hline Antibiotics & 2 & 2.7 \\
\hline Dialysis & 2 & 2.7 \\
\hline Transfusion of blood products & 2 & 2.7 \\
\hline Chemo-therapy or other cancer therapy & 1 & 1.4 \\
\hline Surgery & 1 & 1.4 \\
\hline
\end{tabular}

${ }^{\dagger}$, multiple answers possible, hence percentages do not add up to $100 \%$; ${ }^{\ddagger}$, other medications include: nonsteroidal analgesics, antidiarrheal, antibiotics, steroids and vitamins; ${ }^{\S}, 13$ missing. P.E.G., percutaneous endoscopic gastrostomy; BPAP, bilevel positive airway pressure.
Table 3 Characteristics of end-of-life decision-making by general practitioners for non-sudden deaths

\begin{tabular}{|c|c|c|}
\hline \multirow{2}{*}{ Decision-making } & \multicolumn{2}{|c|}{ Total $(\mathrm{N}=73)$} \\
\hline & $\mathrm{N}$ & $\%$ \\
\hline \multicolumn{3}{|l|}{ Discussion with patient on end-of-life treatment options } \\
\hline No discussion & 45 & 61.6 \\
\hline Yes, discussed with patient ${ }^{\dagger}$ & 28 & 38.4 \\
\hline $\begin{array}{l}\text { About giving medications to alleviate pain and/ } \\
\text { or symptoms }\end{array}$ & 22 & 30.1 \\
\hline About withholding treatment(s) & 10 & 13.7 \\
\hline About withdrawing treatment(s) & 3 & 4.1 \\
\hline \multicolumn{3}{|l|}{$\begin{array}{l}\text { Other caregivers included in discussions on end-of-life } \\
\text { treatment options }^{\dagger}\end{array}$} \\
\hline Patient's partner or relatives & 55 & 75.3 \\
\hline Medical colleague/s & 8 & 11 \\
\hline Nursing staff & 6 & 8.2 \\
\hline Another caregiver & 5 & 6.8 \\
\hline \multicolumn{3}{|l|}{ Patient request for hastened end-of-life } \\
\hline No & 57 & 78.1 \\
\hline Yes $^{\dagger}$ & 6 & 8.2 \\
\hline But not explicitly & 4 & 5.5 \\
\hline Explicitly & 2 & 2.7 \\
\hline I don't know & 10 & 13.7 \\
\hline
\end{tabular}

those who had no formal training $11.1 \%(\mathrm{P}=0.01)$ (Table 4). In general practitioners with formal training, compared to those without, discussions with patients about withholding treatments (25\% compared to $6.7 \%)$ and about giving medications to alleviate pain or symptoms were more likely to occur. Those without formal training tended more often not to discuss any treatment options (75.6\% vs. $39.3 \%, \mathrm{P}=0.002)$. The proportion of general practitioners who had palliative care training also had discussions with other caregivers about end-of-life treatment options more than general practitioners with no training (Table 4). 
Table 4 End-of-life decisions and decision-making for non-sudden deaths in relation to general practitioners' formal training in palliative care

\begin{tabular}{|c|c|c|c|c|c|}
\hline \multirow{2}{*}{ Types of end-of-life decisions } & \multicolumn{5}{|c|}{ Formal palliative care training } \\
\hline & $\mathrm{n}$ & $\%$ & $\mathrm{n}$ & $\%$ & $P$ value \\
\hline \multicolumn{6}{|l|}{ Medications administered in the last 7 days of life } \\
\hline No medications were used to alleviate symptoms & 17 & 37.8 & 8 & 28.6 & 0.42 \\
\hline Morphine or other opioid & 5 & 11.1 & 10 & 35.7 & $0.01^{*}$ \\
\hline Diazepam or other benzodiazepine & 9 & 20 & 4 & 14.3 & 0.54 \\
\hline Dopamine or other vasopressors & 0 & 0 & 1 & 3.6 & ** \\
\hline Laxative & 4 & 8.9 & 5 & 17.9 & 0.26 \\
\hline \multicolumn{6}{|l|}{ Treatments withheld } \\
\hline No & 40 & 88.9 & 26 & 92.9 & - \\
\hline Yes $^{\dagger}$ & 5 & 11.1 & 2 & 7.1 & - \\
\hline Antibiotics & 2 & 4.4 & 0 & 0 & ** \\
\hline Artificial hydration (intravenous line, subcutaneous) & 4 & 8.9 & 1 & 3.6 & 0.34 \\
\hline Artificial nutrition (parenteral nutrition, P.E.G. tube) & 4 & 8.9 & 1 & 3.6 & 0.34 \\
\hline Artificial ventilation (intubation or BPAP) & 2 & 4.4 & 1 & 3.6 & 0.52 \\
\hline Chemo-therapy or other cancer therapy & 1 & 2.2 & 0 & 0 & ** \\
\hline \multicolumn{6}{|l|}{ Discussion with patient on end-of-life treatment options } \\
\hline No & 34 & 75.6 & 11 & 39.3 & $0.002^{*}$ \\
\hline \multicolumn{6}{|l|}{ Yes $^{\dagger}$} \\
\hline About withholding treatment(s) & 3 & 6.7 & 7 & 25 & 0.07 \\
\hline About withdrawing treatment(s) & 0 & 0 & 3 & 10.7 & ** \\
\hline About giving medications to alleviate pain and/or symptoms & 8 & 17.8 & 14 & 50 & $0.004^{*}$ \\
\hline \multicolumn{6}{|l|}{ Discussion with other caregivers on end-of-life treatment options ${ }^{\dagger}$} \\
\hline Medical colleague/s & 3 & 6.7 & 5 & 17.9 & 0.14 \\
\hline Nursing staff & 3 & 6.7 & 3 & 10.7 & 0.54 \\
\hline Another caregiver & 1 & 2.2 & 4 & 14.3 & $0.05^{\star}$ \\
\hline Patient's partner or relatives & 31 & 68.9 & 24 & 85.7 & 0.11 \\
\hline
\end{tabular}

${ }^{\dagger}$, multiple answers possible, hence percentages do not add up to $100 \%$ (Percentages are column); ${ }^{*}, \mathrm{P}$ values $<0.05$ were considered significant; ${ }^{* *}, \mathrm{P}$ values could not be calculated due to empty cells; ${ }^{\ddagger}$, other treatments include: nonsteroidal analgesics, antidiarrheal, antibiotics, steroids and vitamins. P.E.G., percutaneous endoscopic gastrostomy; BPAP, bilevel positive airway pressure. 


\section{Discussion}

\section{Summary of main findings}

This study provides the first data on MELDs on a representative sample of decedents who died at a private home with an end-of-life trajectory in T\&T. Our data shows that most general practitioners $(69.8 \%)$ had no formal palliative care training, and their expertise in endof-life communication with their patients was self-taught and developed through experience over the years. The most prevalent MELDs were the administration of morphine or other opioid $20.5 \%$ and withholding artificial hydration and nutrition $6.8 \%$. A large majority of general practitioners $(61.6 \%)$ did not have any discussions with their patients on end-of-life treatment options but did include the patient's partner or relatives in discussions in most cases $(75.3 \%)$. General practitioners trained in palliative care were more likely to prescribe or administer opioids to their patients in the last 7 days of life, $35.7 \%$ (training) vs. $11.1 \%$ (no training), and discuss with patients about giving medications to alleviate pain or symptoms, 50\% (training) vs. $17.8 \%$ (no training), than general practitioners without training.

\section{Strengths and limitations}

The mortality follow-back approach used in this study is an efficient means to collect national information and to describe the last days and months of life-a time when interviewing dying persons is sensitive, potentially inappropriate and logistically challenging (21). A questionnaire was developed based on an existing validated questionnaire (4) and further validated in $T \& T$ for this study (23). Our sampling frame was (1:2), which is similar to that used in studies done in countries with advanced palliative and end-of-life care systems $(1,24)$, and improves the opportunity for comparison of our findings. Some study limitations include the drawbacks inherent to postal surveys like, recall and response bias (25) and our study cannot exclude such limitations. To mitigate this a reasonably short 3-month lag between a death and the physician receiving a questionnaire was allowed. Possible recall bias could probably be reduced with a shorter delay but was not possible due to the necessary time between a death, medical certification and the CSO receiving the completed certificate. Despite a carefully applied Total Design Method including follow-up mailings (26) our response rate is low (31\%) compared to similar studies in other countries $(1,24)$. The response rate could be related to the efficiency of the postal service, or possibly because general practitioners were unfamiliar with the mailing procedure or a survey on palliative and end-of-life care, or possibly because the cultural norm in $\mathrm{T} \& \mathrm{~T}$ is non-participation in voluntary postal surveys. Although our analysis of the non-response did indicate that the responding population is similar to the non-responding in terms of the known characteristics, we cannot exclude a selective non-response in terms of unknown characteristics. For instance, our obtained sample could be biased toward people who died with a predictable end-of-life trajectory, and responses could have been biased to general practitioners that have an interest in the field of palliative medicine. Also, the sensitive nature of questions could have affected physician self-reporting, as they may have felt they could not be truthful about their own endof-life practices (27). Additionally, selection bias due to sampling cannot be ruled out as incomplete information on some death certificates (for example, decedent age or sex were missing or the certifying general practitioners' name or contact details were illegible) excluded such cases.

\section{Interpretation of the results}

The importance of provider education and training in palliative care can play a critical role in the quality, availability of and access to care, particularly in resourcepoor countries where palliative care services are underdeveloped. Our study shows that relatively few general practitioners have any formal palliative care training and when compared to general practitioners without training, there is a notable difference in MELDs. For example, the former seem to give their patients morphine or other opioid to alleviate pain and symptoms in the last 7 days of life, or discuss with their patients end-of-life treatment options more frequently than general practitioners without training. A cross-national European study that looked at physician attitudes towards end-of-life discussions similarly found an association between palliative care training and their likelihood to discuss the potential life-shortening effect of treatments with patients (28). In another study, palliative care experts, compared to non-experts, withheld artificial nutrition and/or hydration more often and were more inclusive of the patient or family in decision-making (29). Unsurprisingly, this difference might be explained by the better understanding gained from postgraduate training in palliative and end-of-life care, which improved not only physicians' awareness of a problem and willingness to act but also their ability to optimally communicate to the 
benefit of the patient. General practitioners are the main source for formal palliative and end-of-life care provision in T\&T reflecting their important role (20), but to further develop a palliative care culture crucial steps, for example, compulsory formal postgraduate training may be needed to improve end-of-life care capacity and the manner of dying from a terminal illness.

General practitioners involved the patient in discussions on end-of-life treatment options in $38 \%$ of non-sudden death cases, which is higher than similar studies found in Spain (7\%), Italy (10\%), and Belgium (25\%) but lower than in the Netherlands (47\%) (30). The patient's partner or relatives were more often consulted in MELDs $75 \%$ and may reflect a societal norm of not openly discussing death and dying with patients as a means of maintaining hope (31), or possibly because patients prefer not to receive bad news and physicians avoid giving it (32). Further research is warranted to identify associated factors why patients are mostly excluded from MELDs.

Our survey data showed that non-treatment decisions occurred infrequently for home deaths, particularly those that may hasten death, and no life-prolonging treatments were reportedly withdrawn. Compared to a similar study of six western European countries where the average nontreatment decision to withhold treatment was (49\%) (33), our proportion was low $9.6 \%$. Although guidelines are ambiguous (34), forgoing end-of-life treatments like artificial hydration or nutrition could be a cultural taboo in the Caribbean (35) and withholding treatments may be considered life-shortening by physicians and family members $(36,37)$. Evidence supports this notion as $40 \%$ of the goals of care in the last 30 days of non-sudden home deaths in $T \& T$ were to prolong life, maintain function, or even cure (20).

\section{Conclusions}

This study suggests discussions between general practitioners and their patients about end-of-life treatment options is uncommon but general practitioners trained in palliative care appear to share end-of-life decision-making. If they are to continue as the predominant formal care provider, they need appropriate training and policy makers must provide the necessary regulatory support to develop palliative care in $T \& T$.

\section{Acknowledgments}

Authors would like to thank the Trinidad and Tobago Medical Association for acting as a non-partisan thirdparty in receiving and collating questionnaire data. We are also appreciative of the Central Statistical Office for providing access to death certificates and to all the general practitioners who participated in the survey.

Funding: This project was supported by the Research Council of the Vrije Universiteit Brussel: Strategic Research Programs (No. SRP 4).

\section{Footnote}

Reporting Checklist: The authors have completed the STROBE reporting checklist. Available at https://apm. amegroups.com/article/view/10.21037/apm-21-1793/rc

Data Sharing Statement: Available at https://apm.amegroups. com/article/view/10.21037/apm-21-1793/dss

Peer Review File: Available at https://apm.amegroups.com/ article/view/10.21037/apm-21-1793/prf

Conflicts of Interest: All authors have completed the ICMJE uniform disclosure form (available at https://apm. amegroups.com/article/view/10.21037/apm-21-1793/coif). LD serves as an unpaid editorial board member of Annals of Palliative Medicine from January 2013 to June 2021. The other authors have no conflicts of interest to declare.

Ethical Statement: The authors are accountable for all aspects of the work in ensuring that questions related to the accuracy or integrity of any part of the work are appropriately investigated and resolved. Ethics approval was granted by the Ministry of Health of Trinidad and Tobago which does not archive ethics approvals with registration numbers. The study was conducted in accordance with the Declaration of Helsinki (as revised in 2013).

Open Access Statement: This is an Open Access article distributed in accordance with the Creative Commons Attribution-NonCommercial-NoDerivs 4.0 International License (CC BY-NC-ND 4.0), which permits the noncommercial replication and distribution of the article with 
the strict proviso that no changes or edits are made and the original work is properly cited (including links to both the formal publication through the relevant DOI and the license). See: https://creativecommons.org/licenses/by-nc-nd/4.0/.

\section{References}

1. van der Heide A, Deliens L, Faisst K, et al. End-of-life decision-making in six European countries: descriptive study. Lancet 2003;362:345-50.

2. Welie JV, Ten Have HA. The ethics of forgoing lifesustaining treatment: theoretical considerations and clinical decision making. Multidiscip Respir Med 2014;9:14.

3. van Wijmen MP, Pasman HR, Widdershoven GA, et al. Continuing or forgoing treatment at the end of life? Preferences of the general public and people with an advance directive. J Med Ethics 2015;41:599-606.

4. Van Der Maas PJ, Van Delden JJ, Pijnenborg L, et al. Euthanasia and other medical decisions concerning the end of life. Lancet 1991;338:669-74.

5. Olsen ML, Swetz KM, Mueller PS. Ethical decision making with end-of-life care: palliative sedation and withholding or withdrawing life-sustaining treatments. Mayo Clin Proc 2010;85:949-54.

6. Rietjens JA, Deschepper R, Pasman R, et al. Medical endof-life decisions: does its use differ in vulnerable patient groups? A systematic review and meta-analysis. Soc Sci Med 2012;74:1282-7.

7. Eliott J, Olver I. Choosing between life and death: patient and family perceptions of the decision not to resuscitate the terminally ill cancer patient. Bioethics 2008;22:179-89.

8. Wright AA, Zhang B, Ray A, et al. Associations between end-of-life discussions, patient mental health, medical care near death, and caregiver bereavement adjustment. JAMA 2008;300:1665-73.

9. Mack JW, Weeks JC, Wright AA, et al. End-of-life discussions, goal attainment, and distress at the end of life: predictors and outcomes of receipt of care consistent with preferences. J Clin Oncol 2010;28:1203-8.

10. Robinson JH, Callister LC, Berry JA, et al. Patientcentered care and adherence: definitions and applications to improve outcomes. J Am Acad Nurse Pract 2008;20:600-7.

11. Knaul FM, Farmer PE, Krakauer EL, et al. Alleviating the access abyss in palliative care and pain relief-an imperative of universal health coverage: the Lancet Commission report. Lancet 2018;391:1391-454.

12. Clark D, Baur N, Clelland D, et al. Mapping Levels of Palliative Care Development in 198 Countries: The Situation in 2017. J Pain Symptom Manage 2020;59:794807.e4.

13. Sepulveda C, Habiyambere V, Amandua J, et al. Quality care at the end of life in Africa. BMJ 2003;327:209-13.

14. Pastrana T, Vallath N, Mastrojohn J, et al. Disparities in the contribution of low- and middle-income countries to palliative care research. J Pain Symptom Manage 2010;39:54-68.

15. Pastrana T, De Lima L, Eisenchlas J, et al. Palliative care research in Latin America and the Caribbean: from the beginning to the Declaration of Venice and beyond. J Palliat Med 2012;15:352-8.

16. Keirse E, Beguin C, Desmedt M, et al. Organisation of palliative care in Belgium - Supplement. Health Services Research (HSR). Brussels: Belgian Health Care Knowledge Centre (KCE). 2009. KCE reports $115 \mathrm{C}$ (D/2009/10.273/42). Available online: https://kce.fgov. be/sites/default/files/page_documents/d20091027342.pdf. Accessed January 2020.

17. Pivodic L, Pardon K, Van den Block L, et al. Palliative care service use in four European countries: a cross-national retrospective study via representative networks of general practitioners. PLoS One 2013;8:e84440.

18. Borgsteede SD, Graafland-Riedstra C, Deliens L, et al. Good end-of-life care according to patients and their GPs. Br J Gen Pract 2006;56:20-6.

19. Maetens A, Beernaert K, Deliens L, et al. Policy Measures to Support Palliative Care at Home: A Cross-Country Case Comparison in Three European Countries. J Pain Symptom Manage 2017;54:523-529.e5.

20. Jennings N, Chambaere K, Chamely S, et al. Palliative and End-of-Life Care in a Small Caribbean Country: A Mortality Follow-back Study of Home Deaths. J Pain Symptom Manage 2020;60:1170-80.

21. Teno JM. Measuring end-of-life care outcomes retrospectively. J Palliat Med 2005;8 Suppl 1:S42-9.

22. Chambaere K, Bilsen J, Cohen J, et al. A post-mortem survey on end-of-life decisions using a representative sample of death certificates in Flanders, Belgium: research protocol. BMC Public Health 2008;8:299.

23. Jennings N, Chambaere K, Cox Macpherson C, et al. Developing and validating a questionnaire for mortality follow-back studies on end-of-life care and decisionmaking in a resource-poor Caribbean country. BMC Palliat Care 2020;19:123.

24. Chambaere K, Bilsen J, Cohen J, et al. Trends in medical end-of-life decision making in Flanders, Belgium 1998- 
2001-2007. Med Decis Making 2011;31:500-10.

25. Menachemi N, Hikmet N, Stutzman M, et al. Investigating response bias in an information technology survey of physicians. J Med Syst 2006;30:277-82.

26. Dillman DA, Smyth JD, Christian LM. Internet, Phone, Mail, and Mixed-Mode Surveys: The Tailored Design Method. 4th Edition. Hoboken New Jersey: John Wiley \& Sons, Inc, 2014.

27. Merry AF, Moharib M, Devcich DA, et al. Doctors' willingness to give honest answers about end-oflife practices: a cross-sectional study. BMJ Open 2013;3:e002598.

28. Miccinesi G, Fischer S, Paci E, et al. Physicians' attitudes towards end-of-life decisions: a comparison between seven countries. Soc Sci Med 2005;60:1961-74.

29. Robijn L, Cohen J, Rietjens J, et al. Trends in Continuous Deep Sedation until Death between 2007 and 2013: A Repeated Nationwide Survey. PLoS One 2016;11:e0158188.

30. Evans N, Pasman HR, Vega Alonso T, et al. End-of-life decisions: a cross-national study of treatment preference discussions and surrogate decision-maker appointments. PLoS One 2013;8:e57965.

31. Toscani F, Farsides C. Deception, catholicism, and

Cite this article as: Jennings NP, Chambaere K, Macpherson CC, Cox KL, Deliens L, Cohen J. Medical end-of-life decision-making in a small resource-poor Caribbean country: a mortality follow-back study of home deaths. Ann Palliat Med 2022;11(5):1660-1670. doi: 10.21037/apm-21-1793 hope: understanding problems in the communication of unfavorable prognoses in traditionally-catholic countries. Am J Bioeth 2006;6:W6-18.

32. Costantini A, Baile WF, Lenzi R, et al. Overcoming cultural barriers to giving bad news: feasibility of training to promote truth-telling to cancer patients. J Cancer Educ 2009;24:180-5.

33. Bosshard G, Nilstun T, Bilsen J, et al. Forgoing treatment at the end of life in 6 European countries. Arch Intern Med 2005;165:401-7.

34. Druml C, Ballmer PE, Druml W, et al. ESPEN guideline on ethical aspects of artificial nutrition and hydration. Clin Nutr 2016;35:545-56.

35. Jennings N, Chambaere K, Macpherson CC, et al. Main themes, barriers, and solutions to palliative and end-of-life care in the English-speaking Caribbean: a scoping review. Rev Panam Salud Publica 2018;42:e15.

36. Morita T, Shima Y, Adachi I, et al. Attitudes of Japanese physicians toward terminal dehydration: a nationwide survey. J Clin Oncol 2002;20:4699-704.

37. Bükki J, Unterpaul T, Nübling G, et al. Decision making at the end of life--cancer patients' and their caregivers' views on artificial nutrition and hydration. Support Care Cancer 2014;22:3287-99. 


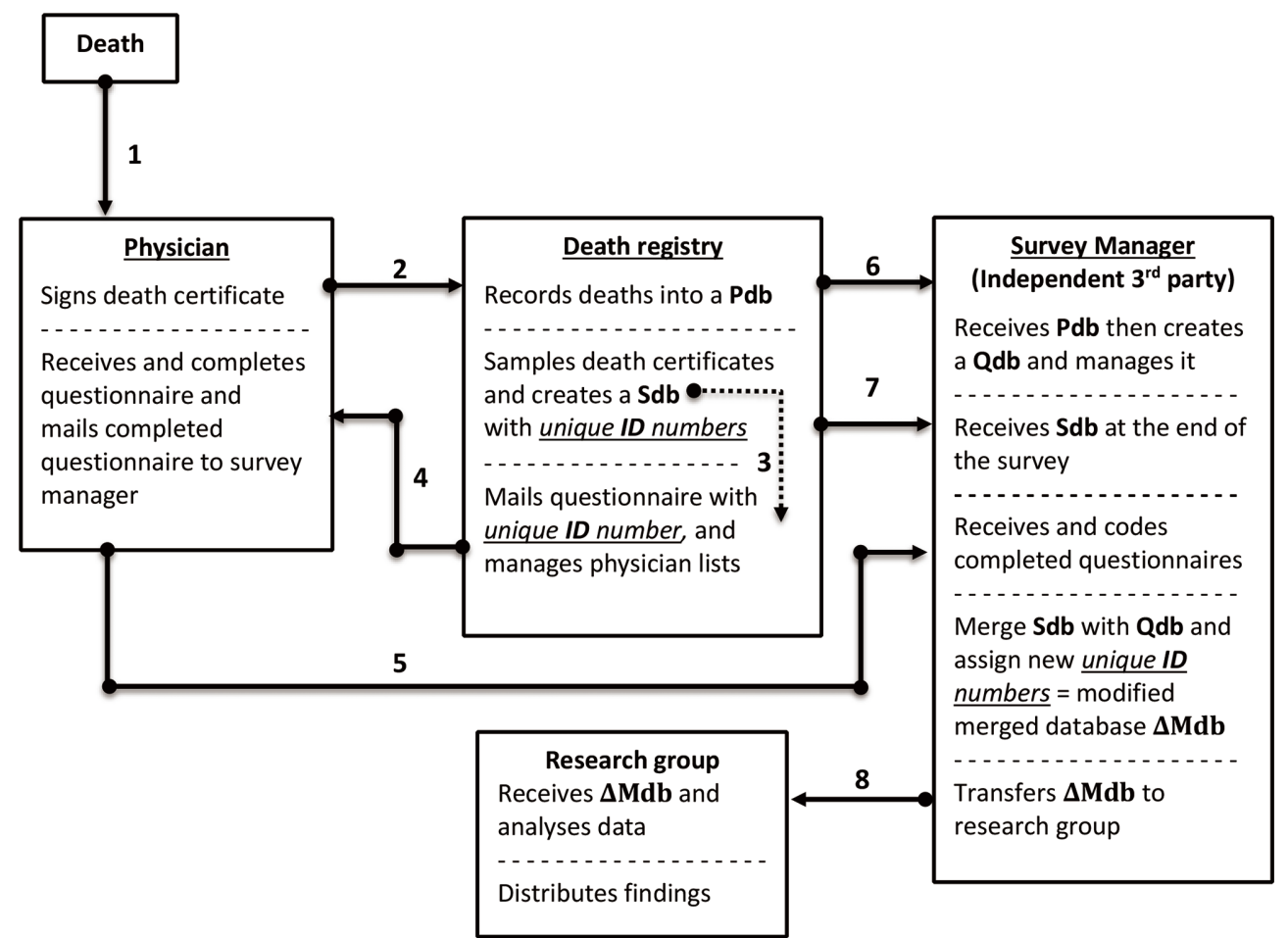

Figure S1 Schematic of mailing procedure. In each rectangular box, the sequence of activities flows from top to bottom, some activities are done intermittently. Palliative and End-of-Life Care in a Small Caribbean Country: A Mortality Follow-back Study of Home Deaths, by N. Jennings et al, 2020, Journal of Pain and Symptom Management. Copyright 2020. Reprinted with permission by American Academy of Hospice and Palliative Medicine, (20). Pbd, population database; Sdb, survey database; ID, identification; Qdb, questionnaire database; $\Delta \mathrm{Mdb}$, merged database. 


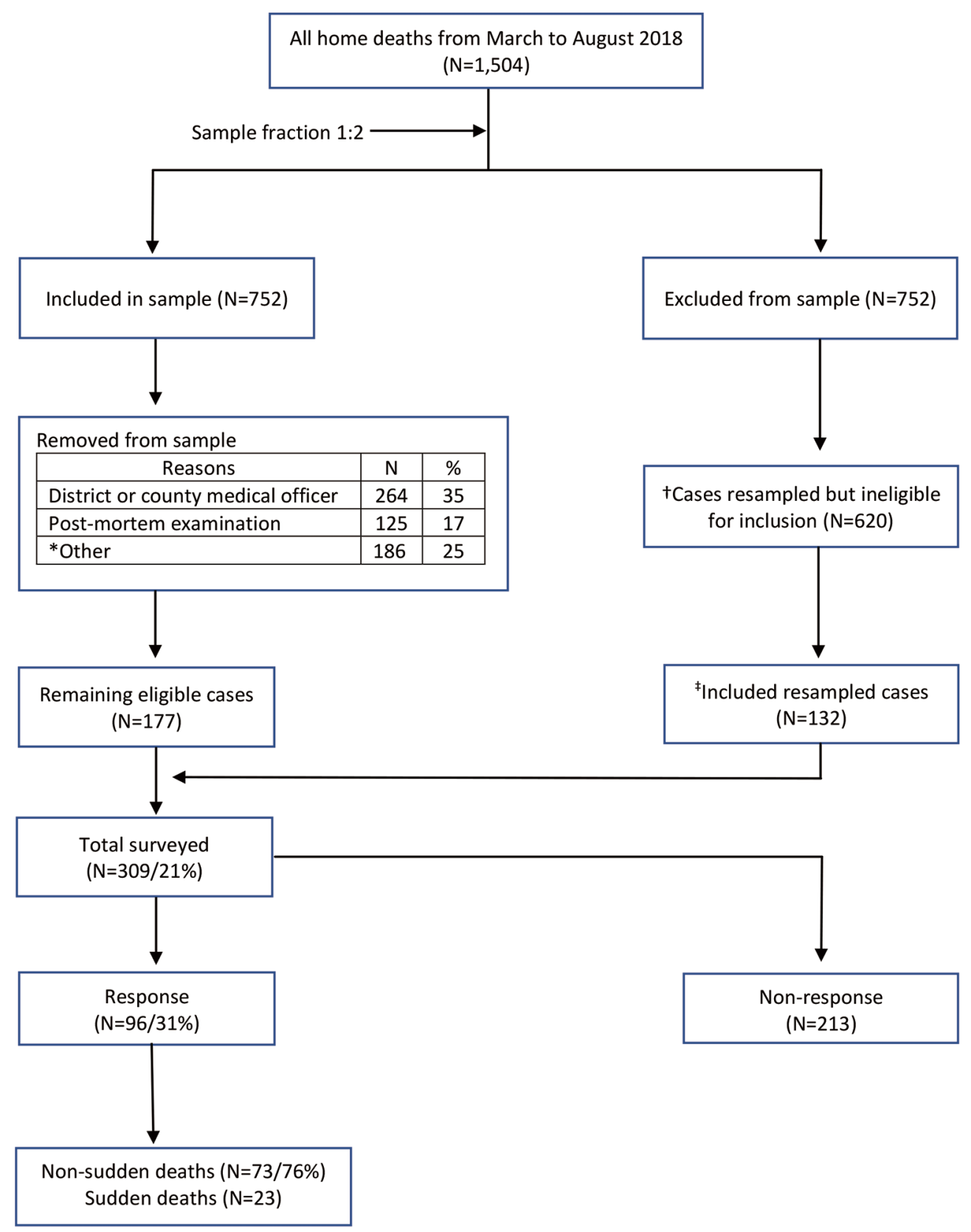

Figure S2 Flowchart of sampled death certificates. Palliative and End-of-Life Care in a Small Caribbean Country: A Mortality Follow-back Study of Home Deaths, by N. Jennings et al, 2020, Journal of Pain and Symptom Management. Copyright 2020. Reprinted with permission by American Academy of Hospice and Palliative Medicine, (20). *, other includes: physician certifying the death case had indicated to not want to participate, physician could not be located, illegible writing on death certificate, and saturation of questionnaires per physician; ${ }^{\dagger}$, cases ineligible for resampling because: death certificates certified by a district or county medical officer, cases transferred for post-mortem examination, cases were past the three-month cut-off time, and reasons listed as 'Other' above (physician did not want to participate, physician could not be located, illegible writing on death certificate, and saturation of questionnaires per physician); ${ }^{\ddagger}$, resampled cases were sequentially selected within the same month of the case that a sample was removed. 
Table S1 Sociodemographic distribution of characteristics of all home deaths surveyed and for all cases that a response was received. Palliative and End-of-Life Care in a Small Caribbean Country: A Mortality Follow-back Study of Home Deaths, by N. Jennings et al., 2020, Journal of Pain and Symptom Management. Copyright 2020. Reprinted with permission by American Academy of Hospice and Palliative Medicine, (20)

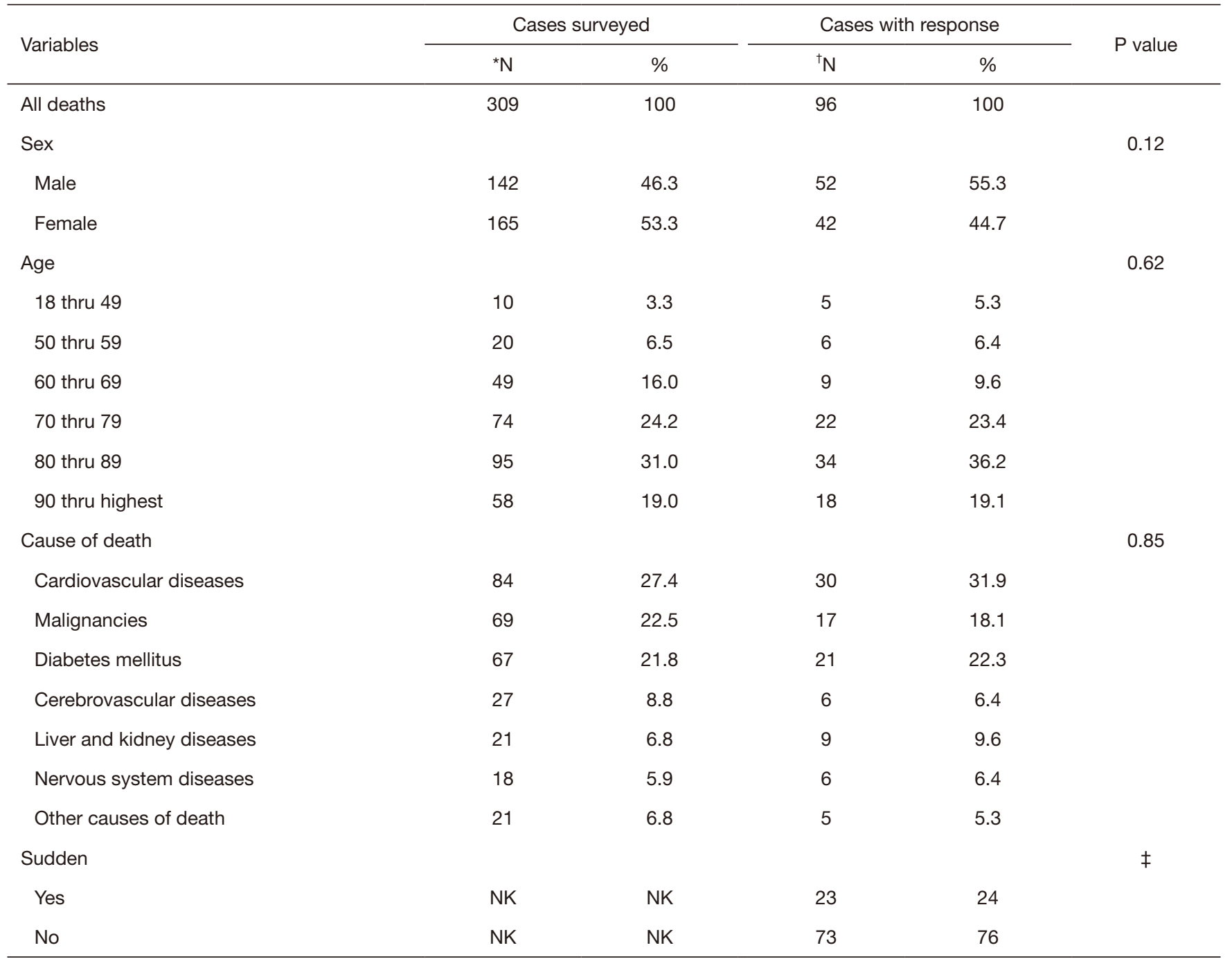

*, 2 missing cases for sex and cause of death, 3 missing cases for age; ${ }^{\dagger}, 2$ missing cases for sex, age and cause of death; ${ }^{\ddagger}, \mathrm{P}$ values could not be calculated due to empty cells. \% are valid percentages. P values $<0.05$ were considered significant. NK, not known. 